• 研究简报・

\title{
川西周公山柳杉人工林群落的边缘效应
}

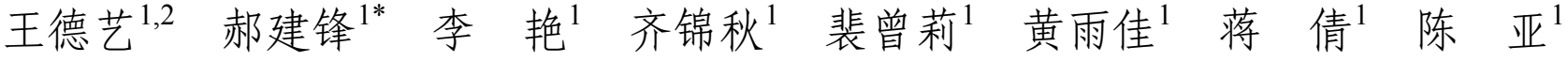 \\ 1 (四川农业大学林学院, 成都 611130) \\ 2 (中国科学院植物研究所系统与进化植物学国家重点实验室, 北京 100093)
}

\begin{abstract}
摘要: 为研究人工林群落的边缘效应特征, 本文以川西周公山森林公园的柳杉(Cryptomeria fortunei) 人工林破碎化 大斑块为对象, 以植株平均胸径、平均高度、平均密度、丰富度指数 $(D)$ 和Shannon-Wiener指数 $(H)$ 来综合衡量边缘 效应深度。在实地踏查的基础上, 从林缘向林内(梯度 1 至梯度 5 )设置 5 条样带(宽度为 $10 \mathrm{~m}$ ), 在每条样带中设置 4 个 $10 \mathrm{~m} \times 10 \mathrm{~m}$ 的小样方进行调查。结果表明: (1)从物种组成上看, 在总面积为 $2,000 \mathrm{~m}^{2}$ 的 20 个小样方中共记录到 111 个物种, 隶属于 54 科 96 属, 物种数从林缘至林内递减。(2)从群落结构上看, 乔木层的平均胸径从林缘至林内呈减 小趋势, 平均密度则相反, 平均高度无显著变化; 灌木层的平均密度从林缘向林内减小, 平均高度无显著变化; 草 本层的平均密度和平均高度均呈减小趋势。(3)从物种多样性上看, 总体上各层次的丰富度指数和 Shannon-Wiener 指数均从林缘向林内呈减小趋势, 其中灌木层和草本层的变化趋势最明显; 同时, 林内各梯度与梯度 1 (林缘)的共 有种和相似性系数从林缘向林内递减。(4)分析各项群落特征发现, 平均高度、平均密度和相似性系数的数值在梯 度2向梯度3过渡时的起伏变化最明显，推断本研究中柳杉人工林斑块的边缘深度可达林内 $20 \mathrm{~m}$ 。
\end{abstract}

关键词: 边缘效应; 柳杉人工林; 物种多样性; 群落结构; 物种组成

\section{Examination of edge effects in a Cryptomeria fortunei plantation in Zhougong Mountain, western Sichuan}

\author{
Deyi Wang ${ }^{1,2}$, Jianfeng $\mathrm{Hao}^{1 *}$, Yan $\mathrm{Li}^{1}$, Jinqiu Qi ${ }^{1}$, Zengli Pei ${ }^{1}$, Yujia Huang ${ }^{1}$, Qian Jiang ${ }^{1}$, Ya Chen ${ }^{1}$ \\ 1 College of Forestry, Sichuan Agricultural University, Chengdu 611130 \\ 2 State Key Laboratory of Systematic and Evolutionary Botany, Institute of Botany, Chinese Academy of Sciences, Beijing \\ 100093
}

\begin{abstract}
To investigate edge effects on community structure, species composition and diversity in an artificial forest, research was conducted on Zhougong Mountain, a forest park in western Sichuan, and a large fragmented plantation of Cryptomeria fortunei was selected as the sample plot. The average DBH (diameter at breast height), average height, average density, richness index $(D)$ and Shannon-Wiener index $(H)$ were used to evaluate edge effects. Based on a field survey, 5 transects (width $=10 \mathrm{~m}$ ) were established from the edge to interior forest (gradient 1 to gradient 5), and 4 small plots $(10 \mathrm{~m} \times 10 \mathrm{~m}$ ) were chosen in each transect using a random sampling method. Results showed that 111 species, belonging to 96 genera and 54 families were recorded in 20 small plots with a total area of $2,000 \mathrm{~m}^{2}$. The following results were also found in this investigation: (1) The number of species decreased away from the edge to forest interior. (2) In terms of community structure, a decrease of average DBH was found in the tree layer with the increase of edge gradients. Average density followed the opposite pattern and no significant differences were found in average height. In the shrub layer, average density decreased with the increase of edge gradients and no significant differences were found in average height. Average density and height both decreased from the edge to interior forest in the herb layer. (3) Based on the analysis of species diversity, richness index $(D)$ and Shannon-Wiener index $(H)$ of the plantation, decreased values were generally found with an increase of edge gra-
\end{abstract}

收稿日期: 2015-12-10: 接受日期: 2016-04-19 基金项目: 四川省教育厅一般项目(自然科学) (15ZB0020)、国家自然科学基金(31370628)、国家科技支撑计划(2011BAC09B05)和四川农业大学双支计 划博士专项基金(00370401)

* 通讯作者 Author for correspondence. E-mail:haojf2005@aliyun.com 
dients, and were much more obvious in the shrub and herb layer. Moreover, the number of common species and Sørensen's similarity coefficient between edge gradients in the forest interior and edge 1 both showed a decreasing trend from the edge to interior forest. (4) Based on a comprehensive analysis, a clear change of community was found between edge 2 and edge 3 , indicating that edge effects can reach $20 \mathrm{~m}$ into the fragmented patch of the Cryptomeria fortunei plantation.

Key words: edge effect; Cryptomeria fortunei plantation; species diversity; community structure; species composition

边缘效应是指在两个或多个不同性质的生态 系统(或其他系统)交互作用处, 由于某些生态因子 (物质、能量、信息、时机或地域)或系统属性的差 异和协同作用而引起系统某些组分及行为(如种群 密度、生产力和多样性等)不同于系统内部的现象 (王如松和马世骏, 1985; 陈利顶等, 2004)。近100年 来, 物种多样性丧失是一个全球性事件, 频繁的人 类活动导致的生境破碎化是物种多样性丧失的主 要原因, 连续的自然生境被破碎化的森林斑块逐渐 代替, 导致林缘面积不断增加(廉振民和于广志, 2000; Damschen et al, 2006; Lindenmayer et al, 2006; Caruso et al, 2011)。边缘效应是生态学和保护生物 学中非常重要的概念(Collinge, 1996; Lindenmayer \& Fischer, 2007; Ewers et al, 2011; Gavish et al, 2012)。在全球范围内, 不管是大空间尺度的气候带 还是微小的群落间, 边缘效应无处不在(陈利顶等, 2004; Ewers \& Didham, 2006; Lindenmayer \& Fischer, 2007)。

大量研究表明, 边缘效应造成植物群落内部和 外部的物种组成和多样性分布不均匀, 其正负效应 与森林斑块的面积、形状、形成的年龄、连通性、 邻近斑块的性质等密切相关, 但关于边缘正负效应 的研究结果不一(Kunin, 1998; 孙雀等, 2008; 乌玉 娜等, 2011; 刘延国等, 2012)。森林斑块边缘效应的 存在使林内至林外的生态环境产生梯度变化, 进而 影响动植物组成和空间分布、群落结构和功能、生 物多样性和稳定性、群落能量流和物质流等 (Watling \& Donnelly, 2006; Tscharntke et al, 2012; Zeng et al, 2012; Kooyman et al, 2013)。在破碎化的 森林斑块中, 由于光照、湿度、土壤等环境因子往 往呈现出由林缘至林内的梯度分布格局, 使得斑块 内部到林缘的距离与边缘效应深度存在相关性, 物 种组成、群落结构和多样性也呈现出从林缘至林内 的梯度变化(Collinge, 1996; 马文章等, 2009; Zeng et al, 2012; 苏晓飞等, 2014)。此外，由于不同植物 或植物功能群对生境破碎化的敏感性不同, 它们对 环境变化的适应策略也大相径庭, 如敏感性和耐受 性物种、乔木种和灌木种、耐阴种和不耐阴种、常 绿种和落叶种等功能群对边缘效应的响应强度不 同, 这使得边缘效应的研究结果不一(Lindenmayer et al, 2005; Aguilar et al, 2006; 田超等, 2011; Tscharntke et al, 2012; Kooyman et al, 2013)。

作为人类生产生活原料的主要来源, 人工林在 世界森林面积中占据绝对优势地位, 但强烈的人为 干扰使其生境十分脆弱且极易破碎化。对于承担着 经济和生态双重任务的人工林而言, 研究其边缘效 应的作用规律和生态阈值(Huggett，2005), 对于平 衡生物多样性保护与林业生产之间的关系, 以及在 森林经营管理过程中制定生物多样性保护策略具 有重要意义。本文以周公山柳杉(Cryptomeria fortunei) 人工林群落的破碎化斑块为对象, 研究边缘 效应的性质和作用规律, 试图回答以下问题: 沿着 林缘到内部, 边缘效应对植物群落结构、物种组成 和多样性的影响如何? 不同植物群落层次对森林 斑块边缘效应的敏感性的差异? 边缘效应从林缘 向林内的效应深度? 旨在为斑块化森林保护策略 的制定、柳杉人工林的合理经营及森林生态系统功 能的发挥提供理论依据。

\section{1 材料与方法}

\section{1 研究区概况}

周公山森林公园 $\left(103^{\circ} 1^{\prime} 1^{\prime \prime}-103^{\circ} 1^{\prime} 48^{\prime \prime} \mathrm{E}\right.$, $29^{\circ} 57^{\prime} 41^{\prime \prime}-29^{\circ} 58^{\prime} 22^{\prime \prime} \mathrm{N}$ ) 是四川省级森林公园, 位于 雅安市区南周公河畔, 青衣江环绕其东、北两面, 属邛崃山脉向南支系, 最高海拔 $1,742.6 \mathrm{~m}$, 呈南北 走向, 长 $9 \mathrm{~km}$, 最宽处 $3 \mathrm{~km}$ 。气候属亚热带湿润季 风气候, 年平均气温 $16.2^{\circ} \mathrm{C}, 7$ 月平均温度 $25.3^{\circ} \mathrm{C}, 1$ 月平均温度 $6.1^{\circ} \mathrm{C}$, 极端最高温度 $37.7^{\circ} \mathrm{C}$, 极端最低 
温度 $-3{ }^{\circ} \mathrm{C}$; 年平均降水量 $1,774.3 \mathrm{~mm}$, 年平均蒸发 量 $1,011.2 \mathrm{~mm}$, 年平均相对湿度 $79 \%$; 年平均日照 时数 $1,039.6 \mathrm{~h}$, 年平均无霜期 $304 \mathrm{~d}$; 土壤为山地黄 壤(周平和丁春邦, 2011)。

因地处四川盆地向青藏高原的过渡带, 周公山 植物资源丰富，原始的植被类型为亚热带常绿阔叶 林。在 20 世纪末期, 速生人工林的大量种植, 周期 性的经济采伐以及与之相伴的林道建设, 使原始植 被严重破碎化。近年来, 虽采伐活动逐渐趋于缓和, 但休闲旅游等人为活动却日益增加, 柳杉人工林的 破碎化并未得到有效控制。目前, 以柳杉为绝对优 势种的柳杉人工林残余斑块是周公山主要的植被 类型，其中柳杉人工林面积达 $500 \mathrm{ha}$, 多为林龄 20 年左右的中熟林及近熟林, 并有少量伴生树种, 如 杉木 (Cunninghamia lanceolata)、马尾松 (Pinus massoniana)、新木姜子(Neolitsea aurata)、枹栎 (Quercus serrata)、木荷(Schima superba)、桤木(Alnus cremastogyne) 等。林下植被稀疏, 物种组成较为单 一, 灌木层主要有刚竹(Phyllostachys sulphurea)、寒 莓 (Rubus buergeri) 等, 草本层主要有里白 (Hicriopteris glauca)、中华蹄盖䓲 (Athyrium sinense)、狗脊(Woodwardia japonica)、南方复叶耳 蕨(Arachniodes australis)等偋类植物。

\section{2 研究方法}

\subsection{1 样地的设置与调查}

选择边缘形状较规则的大斑块设置实验样地 (海拔 1,040-1,100 m, 坡度 $9^{\circ}-14^{\circ}$ )。由林缘向内至斑 块中心共设置 5 条 $10 \mathrm{~m}$ 宽的样带, 用边缘梯度来表 示斑块从林缘到内部的距离, 每隔 $10 \mathrm{~m}$ 为一个梯 度, 即0-10 m为边缘梯度 $1,10-20 \mathrm{~m}$ 为边缘梯度 2 , 依次类推到梯度 5 。在每条样带中选取 4 个 $10 \mathrm{~m} \times 10$ $\mathrm{m}$ 的小样方, 以小样方作为基本调查单位, 测定和 记录其中的所有乔木和灌木。将小样方等分为 4 个 5 $\mathrm{m} \times 5 \mathrm{~m}$ 样格, 在每个样格中随机测定 2 个 $1 \mathrm{~m} \times 1 \mathrm{~m}$ 的草本样方。参照方精云等(2009), 分别测定乔木、 灌木、草本的株数、高度、胸径、冠幅、盖度等 指标。

\subsection{2 数据处理}

(1)物种多样性指数。参照刘灿然等(1998)的生 物群落多样性测度方法, 根据调查数据计算物种丰 富度指数 ( $D$, 用物种数表示) 和Shannon-Wiener多样 性指数 $(H)$ :

$$
H=-\sum_{i=1}^{S} P_{i} \log P_{i}
$$

式中, $P_{i}$ 为第 $i$ 种的个体数 $n$ 占所有种个体总数 $n$ 的比 例, 即 $P_{\mathrm{i}}=n_{\mathrm{i}} / n ; i=1,2,3, \ldots, S, S$ 为物种数。

(2)相似性系数。参照赵永华等 (2004), 用 Sørensen相似性系数 $\left(S_{S}\right)$ 表示各样带间物种组成的 相似性:

$$
S s=2 a /(2 a+b+c)
$$

式中, $a$ 为两个样方中的共有物种数, $b$ 为甲样方有 而乙样方没有的物种数, $c$ 为乙样方有而甲样方没 有的物种数。

利用Origin 8.0、SPSS 19.0软件和Excel进行数 据分析和图表制作, 利用单因素方差分析(One-way ANOVA)比较不同边缘梯度间的差异, 显著性水平 设定为 $P=0.05$ 。

\section{2 结果}

\section{1 柳杉人工林斑块的物种组成}

在5条调查样带中共记录到 111 个物种，隶属于 54科96属(图1)。从群落层次上看, 灌木最多, 草本 次之, 乔木最少。从不同边缘梯度来看, 随着边缘 梯度的增加, 物种数呈减少趋势, 梯度 1 最多, 梯度 5 最少(图2)。

\section{2 柳杉人工林斑块的群落结构}

\subsection{1 乔木层平均胸径}

周公山柳杉人工林中乔木的胸径随着边缘梯 度的增加，总体上呈减小趋势; 梯度 $1 、 2$ 与梯度 $3 、$

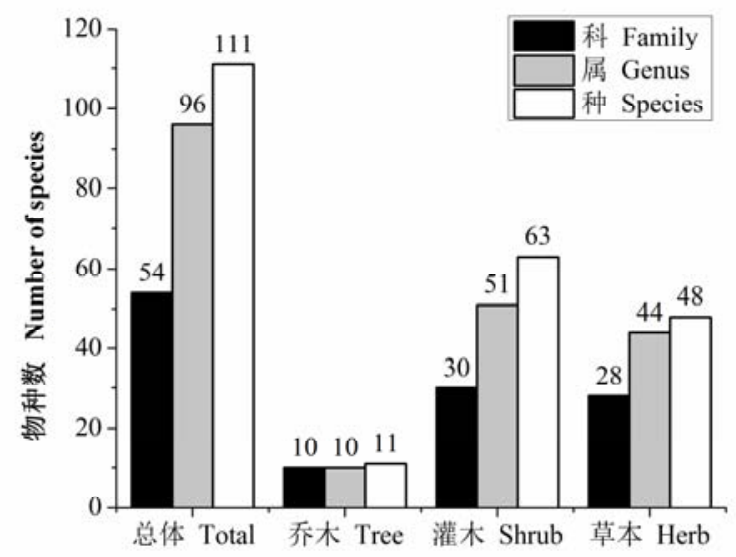

图1 柳杉人工林群落的物种组成

Fig. 1 Composition of species, genus and family in Cryptomeria fortunei plantation 


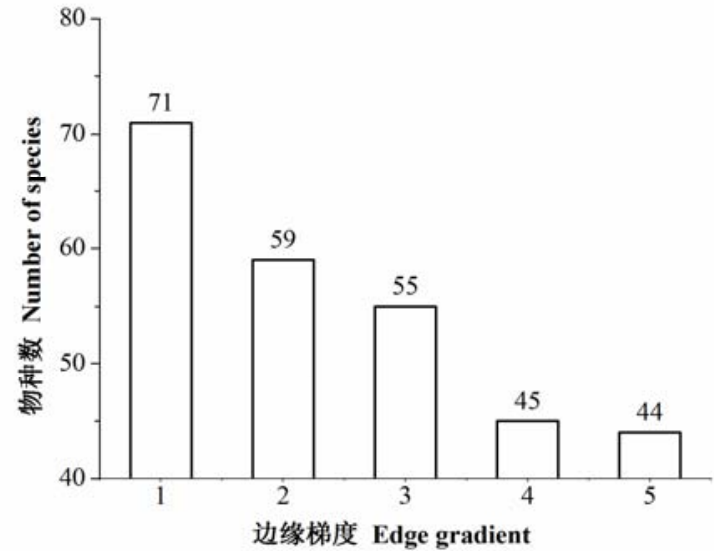

图2 柳杉人工林各边缘梯度的物种数

Fig. 2 Number of species of each edge gradient in Cryptomeria fortunei plantation

4、5差异显著, 乔木个体在林缘(梯度1)的径向生长 旺盛(图3)。

\subsection{2 平均高度}

周公山柳杉人工林各层次的平均高度对边缘 梯度的响应不一(图3和图4)。在乔木层和灌木层中, 随着边缘梯度的增加, 平均高度的变化趋势不明 显, 各梯度间差异不显著; 在草本层中, 随着边缘 梯度的增加, 平均高度呈波动减小的趋势, 梯度 1 与梯度 5 之间差异显著。

\subsection{3 平均密度}

周公山柳杉人工林各层次的平均密度在不同 边缘梯度下差异显著(图5)。在乔木层中, 随着边缘 梯度的增加, 平均密度总体上呈增加趋势, 梯度 1 和梯度 2 与梯度 5 差异显著。在灌木层中, 随着边缘 梯度的增加, 平均密度总体上呈减小趋势, 梯度 1 与梯度 5 差异显著。在草本层中, 随着边缘梯度的增 加, 平均密度呈减小趋势, 梯度 1 和梯度 2 与梯度 5 的数值差异显著。

\section{3 柳杉人工林斑块的物种多样性指数和相似性} 系数

\subsection{1 物种多样性指数}

不同层次的丰富度指数 $(D)$ 和Shannon-Wiener 指数 $(H)$ 对边缘梯度的响应不一致(图6)。在乔木层 中, 各梯度的 $D$ 和 $H$ 随着边缘梯度的增加无显著变 化。在灌木层中, 随着边缘梯度的增加, $D$ 递减, 梯 度 $1 、 2 、 3$ 与梯度4、5 差异显著; $H$ 的波动较小, 各 梯度间无显著差异。在草本层中, $D$ 和 $H$ 均递减, 梯

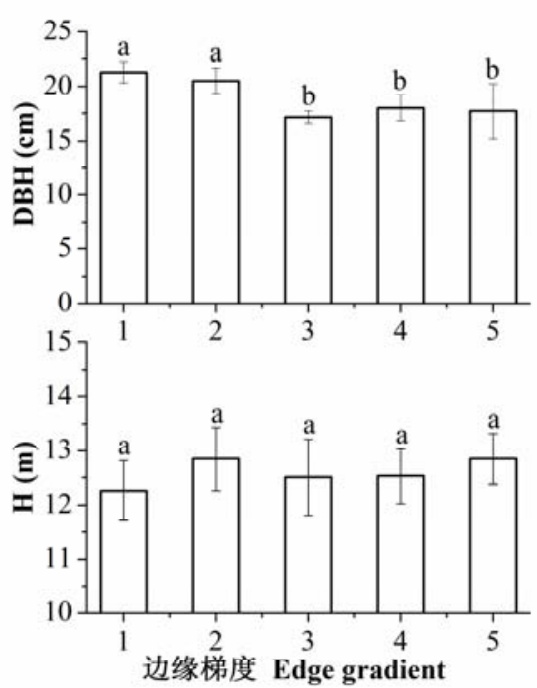

图3 不同边缘梯度下周公山柳杉人工林乔木层的平均胸径 $(\mathrm{DBH})$ 和平均高度 $(\mathrm{H})$ (平均值沶准差)。不同小写字母表示 梯度间差异显著 $(\boldsymbol{P}<\mathbf{0 . 0 5})$ 。

Fig. 3 The average diameter at breast height (DBH) and average height $(\mathrm{H})$ in the tree layer of Cryptomeria fortunei plantation of different edge gradients (mean $\pm \mathrm{SD}$ ). Different small letters mean significant difference at 0.05 level among gradients.

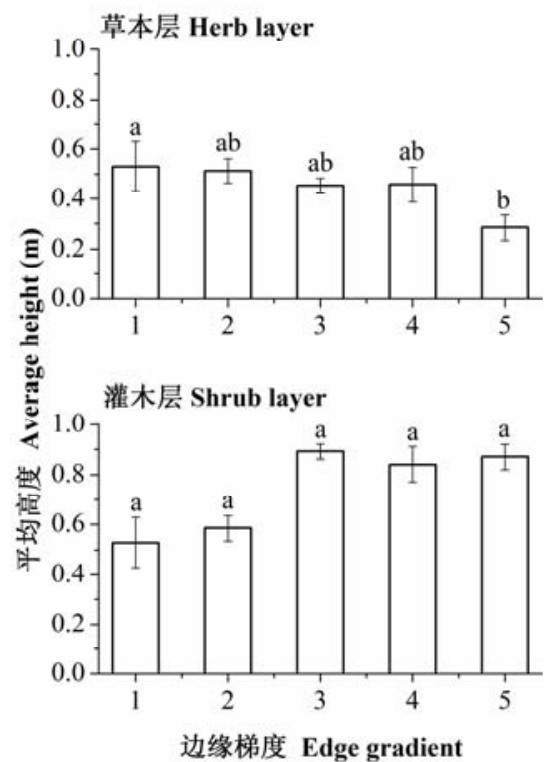

图4 不同边缘梯度下柳杉人工林灌木层和草本层的平均高 度(平均值士标准差)。不同小写字母表示梯度间差异显著 $(\boldsymbol{P}<$ 0.05)。

Fig. 4 The average height in shrub and herb layers of Cryptomeria fortunei plantation of different edge gradients. Different small letters mean significant difference at 0.05 level among gradients. 

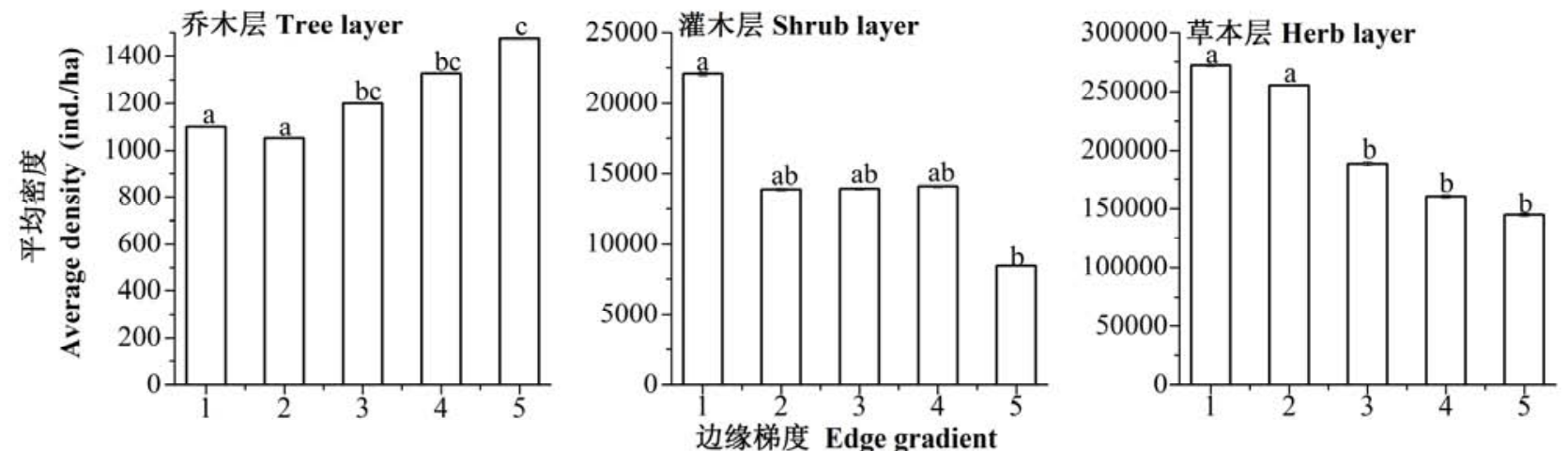

图5 不同边缘梯度下柳杉人工林不同层次的平均密度(平均值标准差)。不同小写字母表示梯度间差异显著 $(\boldsymbol{P}<\boldsymbol{0 . 0 5})$ 。

Fig. 5 The average density in different layers of Cryptomeria fortunei plantation of different edge gradients. Different small letters mean significant difference at 0.05 level among gradients.
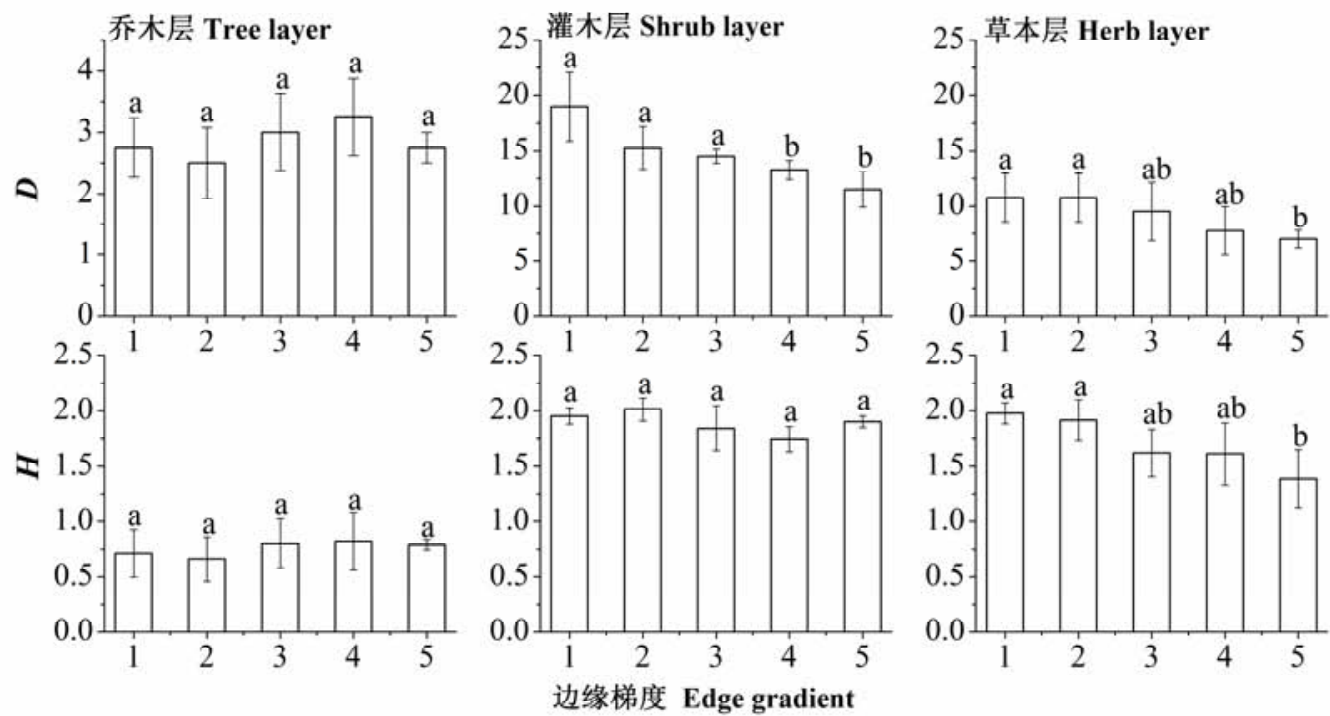

图6 柳杉人工林各层次的丰富度指数 $(\boldsymbol{D})$ 值和Shannon-Wiener指数 $(\boldsymbol{H})$ (平均值土标准差)。不同小写字母表示梯度间的 $D$ 或 $H$ 值差异显著 $(P<\mathbf{0 . 0 5})$ 。

Fig. 6 Richness index $(D)$ and Shannon-Wiener index $(H)$ in different layers of Cryptomeria fortunei plantation of different edge gradients. Different small letters mean significant difference of $D(H)$ at 0.05 level among gradients.

度 $1 、 2$ 与梯度 5 差异显著。

\subsection{2 相似性系数}

分析毗邻的边缘梯度间的共有植物种数和相 似性系数发现, 随着边缘梯度的增加, 共有种数总 体上呈减少趋势, 相似性系数呈先减小后增加的趋 势(表1), 从林缘至林内梯度间的物种组成的异质性 呈先增加后减小的趋势。分析梯度2-5与梯度 1 的共 有种和相似性系数发现, 随着边缘梯度的增加, 其 他梯度与梯度 1 的共有种数和相似性系数均呈减少 趋势(表2), 林内梯度与林缘的物种组成的异质性与
至林缘的距离呈负相关关系。

\section{3 讨论}

\section{1 物种多样性的梯度变化}

边缘效应对生物多样性的影响有正效应和负 效应(王如松和马世骏, 1985), 斑块边缘生境的生物 和非生物因子的特殊性导致了一定时期内物种的 边缘聚集效应，因此边缘效应多表现为林缘的高物 种多样性，并随着与林缘距离的增加，物种多样性 水平降低, 林缘与林内之间的相似性系数降低 
表1 柳杉人工林毗邻的边缘梯度间的共有植物种数与Sørensen相似性系数

Table 1 The number of common species and Sørensen's similarity coefficient between adjacent edge gradients in Cryptomeria fortunei plantation

\begin{tabular}{|c|c|c|c|c|}
\hline 两两边缘梯度之间 & 梯度1-梯度2 & 梯度2-梯度3 & 梯度3-梯度4 & 梯度4-梯度5 \\
\hline Between edge gradients & Gradient 1 -gradient 2 & Gradient 2 -gradient 3 & Gradient 3 -gradient 4 & Gradient 4 -gradient 5 \\
\hline 共有种数 Number of common species & 45 & 34 & 27 & 31 \\
\hline 相似性系数 Sørensen's similarity coefficient & 0.69 & 0.60 & 0.54 & 0.67 \\
\hline
\end{tabular}

表2 柳杉人工林其他边缘梯度与梯度 1 的共有植物种数与Sørensen相似性系数

Table 2 The number of common species and Sørensen's similarity coefficient between gradient 1 and the other edge gradients in Cryptomeria fortunei plantation

\begin{tabular}{lllll}
\hline 两两边缘梯度之间 & 梯度1-梯度2 & 梯度1-梯度3 & 梯度1-梯度4 & 梯度1-梯度5 \\
Between edge gradients & Gradient 1-gradient 2 & Gradient 1-gradient 3 & Gradient 1-gradient 4 & Gradient 1-gradient 5 \\
\hline 共有种数 Number of common species & 45 & 35 & 29 & 30 \\
相似性系数 Sørensen's similarity coefficient & 0.69 & 0.56 & 0.50 & 0.52 \\
\hline
\end{tabular}

(Kunin, 1998; Ewers \& Didham, 2006; Tscharntke et al, 2012; Zeng et al, 2012)。在本研究中, 从林缘向林 内(梯度 1 至梯度 5$)$, 周公山柳杉人工林斑块的物种 丰富度指数和多样性指数呈梯度降低趋势, 物种数 逐渐减少, 梯度间的共有种数量减少, 林内与林缘 物种组成的差异越来越大。本研究结果与大多数的 研究一致(Damschen et al, 2006; Lindenmayer \& Fischer, 2007; Zeng et al, 2012)。在柳杉人工林斑块 中, 从林缘至林内, 物种多样性的梯度变化与环境 因子的梯度变化呈正相关, 这是因为林缘的乔木个 体较少, 林分郁闭度低, 光照条件较好, 维持了较 高的物种丰富度和多样性; 而林内则相反, 乔木个 体数多, 林分郁闭度高, 光照、水分等条件差, 因此 物种多样性低。

\section{2 不同生活型植物对生境破碎化的敏感性和适 应策略}

在森林破碎化斑块中, 物种组成、丰富度和多 样性指数是所有物种个体对边缘效应响应的总体 情况, 不同研究的结果也有差异。一些研究发现, 即使在同一研究区域中, 同属的不同物种由于生活 史策略和对生境的要求不同, 其对边缘效应的响应 甚至呈现出相反的趋势(Ewers \& Didham, 2006)。对 动物而言, 营养级高且专性取食、扩散能力弱, 或 依赖于互利共生者的物种对破碎化耐受性差, 易于 因生境丧失而灭绝(Ewers \& Didham, 2006)。植物与 动物相似, 有研究表明, 乔木、灌木和草本在有限 的林分空间内产生生态位的分化(牛克昌等, 2009), 它们的种内和种间关系不同, 生存策略不同, 且不
同植物对光照、湿度、土壤等环境因子具有偏好性, 因此它们对生境破碎化后的响应亦不同(Zeng et al, 2012; 苏晓飞等, 2014)。例如，马文章等(2008)研究 发现, 在受到人为干扰的哀牢山常绿阔叶林中, 附 生苔藓比附生硕类对边缘效应更为敏感, 故建议将 对环境变化敏感的附生植物作为环境指示物。

Kooyman等(2013)研究发现, 亚热带雨林中的攀援 性植物相对于非攀援性木本植物对生境破碎化的 敏感性更高。

本研究中, 柳杉人工林灌木层和草本层的丰富 度指数和Shannon-Wiener指数对边缘效应的反应最 为明显, 说明林下植物对环境因子(光、热、水等) 变化的敏感性高于上层乔木。同时, 不同层次的物 种在有限的破碎化生境内的竞争加剧, 为争夺有限 的光热水等条件各自采取了不同的适应策略。乔木 层的平均密度从林缘向林内递增, 而平均胸径则相 反, 说明优势树种柳杉为应对人工林斑块内部的环 境, 采取了增加个体数量和抑制径向生长的适应策 略; 林缘的乔木的适应策略则相反。对灌木而言, 平均密度在林缘较大, 这是因为林缘的上层乔木的 覆盖度较小, 灌木具有更多的生存空间。对草本而 言, 物种组成多以环境耐受性强的蕨类植物为主。 因此，只有在理解不同物种具有不同的特性的基础 上, 才能理解生境破碎化研究相关文献中相互矛盾 的结果。

\section{3 关于人工林经营的建议}

在森林群落中, 尤其是破碎化的森林斑块中, 量化物种丰富度和多样性水平, 研究群落结构的动 
态变化, 可为破碎化森林管理方案的制定和物种多 样性的保护提供有益参考(Kooyman et al, 2013)。在 柳杉人工林破碎化大斑块中, 综合分析物种丰富度 指数、多样性指数、相似性系数、平均胸径、平均 高度、平均密度等群落特征发现, 斑块边缘维持了 较高的物种多样性。平均高度、平均密度和相似性 系数等群落特征从林缘向林内的递减趋势明显; 然 而, 距林缘超过 $20 \mathrm{~m}$ 后, 各群落特征的递减趋势变 弱, 说明边缘效应递减范围可达林内 $20 \mathrm{~m}$ 。如何在 理解边缘效应作用规律的基础上, 合理利用边缘效 应为实现人工林的生态和经济价值服务? 田超等 (2011)认为, 可将边缘效应递减规律用于带状种植、 设计植物的幅宽: 凡发生正边缘效应的植物, 其幅 宽应窄于正边缘效应递减范围的2倍; 凡发生负边 缘效应的植物, 其幅宽应大于负边缘效应递减范围 的 2 倍, 以提高林木的经济效益和生态效益。因此, 周公山柳杉人工林的可持续经营可利用边缘的正 效应，采取疏伐、林窗抚育等措施，促进林内环境 条件的改善。此外, 为避免加剧斑块化过程, 可恢 复林分中残留的木荷、枹栎、新木姜子等本土树种, 尽量以 $20 \mathrm{~m}$ 的间隔距离营造混交林, 以充分发挥这 些阔叶树种的绿色廊道功能，间接恢复周公山的物 种多样性。

\section{参考文献}

Aguilar R, Ashworth L, Galetto L, Aizen MA (2006) Plant reproductive susceptibility to habitat fragmentation: review and synthesis through a meta-analysis. Ecology Letters, 9, 968-980.

Caruso A, Rudolphi J, Rydin H (2011) Positive edge effects on forest-interior cryptogams in clear-cuts. PLoS ONE, 6, e27936.

Chen LD, Xu JY, Fu BJ, Lü YH (2004) Quantitative assessment of patch edge effects and its ecological implications. Acta Ecologica Sinica, 24, 1827-1832. (in Chinese with English abstract) [陈利顶, 徐建英, 傅伯杰, 吕一河 (2004) 斑块边缘效应的定量评价及其生态学意义. 生态 学报, 24, 1827-1832.]

Collinge SK (1996) Ecological consequences of habitat fragmentation: implications for landscape architecture and planning. Landscape and Urban Planning, 36, 59-77.

Damschen EI, Haddad NM, Orrock JL, Tewksbury JJ, Levey DJ (2006) Corridors increase plant species richness at large scales. Science, 313, 1284-1286.

Ewers RM, Didham RK (2006) Confounding factors in the detection of species responses to habitat fragmentation. Biological Reviews, 81, 117-142.
Ewers RM, Didham RK, Fahrig L, Ferraz G, Hector A, Holt RD, Kapos V, Reynolds G, Sinun W, Snaddon JL, Turner EC (2011) A large-scale forest fragmentation experiment: the stability of altered forest ecosystems project. Philosophical Transactions of the Royal Society B: Biological Sciences, 366, 3292-3302.

Fang JY, Wang XP, Shen ZH, Tang ZY, He JS, Yu D, Jiang Y, Wang ZH, Zheng CY, Zhu JL, Guo ZD (2009) Methods and protocols for plant community inventory. Biodiversity Science, 17, 533-548. (in Chinese with English abstract) [方精 云, 王襄平, 沈泽吴, 唐志尧, 贺金生, 于丹, 江源, 王志 恒, 郑成洋, 朱江玲, 郭兆迪 (2009) 植物群落清查的主 要内容、方法和技术规范. 生物多样性, 17, 533-548.]

Gavish Y, Ziv Y, Rosenzweig ML (2012) Decoupling fragmentation from habitat loss for spiders in patchy agricultural landscapes. Conservation Biology, 26, 150-159.

Huggett AJ (2005) The concept and utility of "ecological thresholds" in biodiversity conservation. Biological Conservation, 124, 301-310.

Kooyman RM, Zanne AE, Gallagher RV, Cornwell W, Rossetto M, O'Connor P, Parkes EA, Catterall CF, Laffan SW, Lusk CH (2013) Effects of growth form and functional traits on response of woody plants to clearing and fragmentation of subtropical rainforest. Conservation Biology, 27, $1468-1477$.

Kunin WE (1998) Biodiversity at the edge: a test of the importance of spatial "mass effects" in the Rothamsted Park grass experiments. Proceedings of the National Academy of Sciences, USA, 95, 207-212.

Lian ZM, Yu GZ (2000) Edge effect and biodiversity. Chinese Biodiversity, 8, 120-125. (in Chinese with English abstract) [廉振民, 于广志 (2000) 边缘效应与生物多样性. 生物 多样性, 8, 120-125.]

Lindenmayer DB, Fischer J (2007) Tackling the habitat fragmentation panchreston. Trends in Ecology and Evolution. 22, 127-132.

Lindenmayer DB, Fischer J, Cunningham RB (2005) Native vegetation cover thresholds associated with species responses. Biological Conservation, 124, 311-316.

Lindenmayer DB, Franklin JF, Fischer J (2006) General management principles and a checklist of strategies to guide forest biodiversity conservation. Biological Conservation, 131, 433-445.

Liu CR, Ma KP, Lü YH, Kang YL (1998) Measurement of biotic diversity. VI. The statistical aspects of diversity measures. Chinese Biodiversity, 6, 229-239. (in Chinese with English abstract) [刘灿然, 马克平, 吕延华, 康永亮 (1998) 生物群落多样性的测度方法.VI. 与多样性测度有 关的统计问题. 生物多样性, 6, 229-239.]

Liu YG, Wang Q, Wang J (2012) Landscape pattern and patch stability in Jiuzhaigou Nature Reserve. Journal of Northeast Forestry University, 40(4), 31-33. (in Chinese with English abstract) [刘延国, 王青, 王军 (2012) 九寨沟自然保护区 景观格局及其斑块稳定性. 东北林业大学学报, 40(4), 
31-33.]

Ma WZ, Liu WY, Yang LP, Yang GP (2008) Edge effects on epiphytes in montane moist evergreen broad-leaved forest. Biodiversity Science, 16, 245-254. (in Chinese with English abstract) [马文章, 刘文耀, 杨礼攀, 杨国平 (2008) 边缘 效应对山地湿性常绿阔叶林附生植物的影响. 生物多样 性, 16, 245-254.]

Niu KC, Liu YN, Shen ZH, He FL, Fang JY (2009) Community assembly: the relative importance of neutral theory and niche theory. Biodiversity Science, 17, 579-593. (in Chinese with English abstract) [牛克昌, 刘怿宁, 沈泽昊, 何芳良, 方精云 (2009) 群落构建的中性理论和生态位理论. 生 物多样性, 17, 579-593.]

Su XF, Yuan JY, Hu YG, Xu GF, Yu JM (2014) Edge effect of plant community structure on land-bridge island in the Thousand Island Lake. Chinese Journal of Applied Ecology, 25, 77-84. (in Chinese with English abstract) [苏晓飞, 袁 金凤，胡摇广，徐高福，于明坚 (2014) 千岛湖陆桥岛屿 植物群落结构的边缘效应. 应用生态学报, 25, 77-84.]

Sun Q, Lu JB, Wu JG, Zhang FF (2008) Effects of island area on plant species distribution and conservation implications in the Thousand Island Lake region. Biodiversity Science, 16, 1-7. (in Chinese with English abstract) [孙雀, 卢剑波, 邬建国, 张凤凤 (2008) 千岛湖库区岛屿面积对植物分 布的影响及植物物种多样性保护研究. 生物多样性, 16 , 1-7.]

Tian C, Yang XB, Liu Y (2011) Edge effect and its impacts on forest ecosystem: a review. Chinese Journal of Applied Ecology, 22, 2184-2192. (in Chinese with English abstract) [田超, 杨新兵, 刘阳 (2011) 边缘效应及其对森林生态 系统影响的研究进展. 应用生态学报, 22, 2184-2192.]

Tscharntke T, Tylianakis JM, Rand TA, Didham RK, Fahrig L, Batáry P, Bengtsson J, Clough Y, Crist TO, Dormann CF, Ewers RM, Fründ J, Holt RD, Holzschuh A, Klein AM, Kleijn D, Kremen C, Landis DA, Laurance W, Lindenmayer
D, Scherber C, Sodhi N, Steffan-Dewenter I, Thies C, van der Putten WH, Westphal C ( 2012) Landscape moderation of biodiversity patterns and processes - eight hypotheses. Biological Reviews, 87, 661-685.

Wang RX, Ma SJ (1985) Edge effect and its application in economic ecology. Chinese Journal of Ecology, (02), 38-42. (in Chinese with English abstract) [王如松, 马世骏 (1985) 边缘效应及其在经济生态学中的应用. 生态学杂志, (02), 38-42.]

Watling JI, Donnelly MA (2006) Fragments as islands: a synthesis of faunal responses to habitat patchiness. Conservation Biology, 20, 1016-1025.

Wu YN, Tao JP, Xi WM, Zhao K, Hao JH (2011) The edge effects on tree-liana relationship in a secondary natural forest in Bawangling Nature Reserve, Hainan Island, China. Acta Ecologica Sinica, 31, 3054-3059. (in Chinese with English abstract) [乌玉娜, 陶建平, 奚为民, 赵科, 郝建辉 (2011) 海南霸王岭天然次生林边缘效应下木质藤本与树 木的关系. 生态学报, 31, 3054-3059.]

Zeng SL, Zhang TT, Gao Y, Li B, Fang CM, Flory SL, Zhao B (2012) Road effects on vegetation composition in a saline environment. Journal of Plant Ecology, 5, 206-218.

Zhao YH, Lei RD, He XY, Jia X (2004) Niche characteristics of plant populations in Quercus aliena var. acuteserrata stands in Qinling Mountains. Chinese Journal of Applied Ecology, 15, 913-918. (in Chinese with English abstract) [赵永华, 雷瑞德, 何兴元, 贾夏 (2004) 秦岭锐齿栋林种 群生态位特征研究. 应用生态学报, 15, 913-918.]

Zhou P, Ding CB (2011) Floristic analysis of seed plants in Zhougong Mountain Forest Park. Journal of Sichuan Forestry Science and Technology, 32, 103-106. (in Chinese with English abstract) [周平, 丁春邦 (2011) 雅安周公山 森林公园种子植物及其区系特征. 四川林业科技，32, 103-106.] 